\title{
Emerging COVID-19 impacts, responses, and lessons for building resilience in the seafood system
}

\author{
David C. Love ${ }^{\mathrm{a}, \mathrm{b},{ }^{*}}$, Edward H. Allison ${ }^{\mathrm{c}}$, Frank Asche ${ }^{\mathrm{d}, \mathrm{e}, \mathrm{f}}$, Ben Belton ${ }^{\mathrm{c}, \mathrm{g}}$, Richard S. Cottrell ${ }^{\mathrm{h}, \mathrm{i}}$, \\ Halley E. Froehlich ${ }^{\mathrm{j}, \mathrm{k}}$, Jessica A. Gephart ${ }^{1}$, Christina C. Hicks ${ }^{\mathrm{m}}$, David C. Little ${ }^{\mathrm{n}}$, \\ Elizabeth M. Nussbaumer ${ }^{\mathrm{a}}{ }^{\mathrm{b}}$, Patricia Pinto da Silva ${ }^{\circ}$, Florence Poulain ${ }^{\mathrm{p}}$, Angel Rubio ${ }^{\mathrm{q}}$, \\ Joshua S. Stoll ${ }^{\mathrm{r}}$, Michael F. Tlusty ${ }^{\mathrm{s}}$, Andrew L. Thorne-Lyman ${ }^{\mathrm{a}, \mathrm{b}, \mathrm{t}}$, Max Troell ${ }^{\mathrm{u}, \mathrm{v}}$, \\ Wenbo Zhang ${ }^{\mathrm{w}}$
}

${ }^{\text {a }}$ Center for a Livable Future, Johns Hopkins University, Baltimore, MD, 21202, USA

${ }^{\mathrm{b}}$ Department of Environmental Health and Engineering, Bloomberg School of Public Health, Johns Hopkins University, Baltimore, MD, 21205, USA

${ }^{\mathrm{c}}$ WorldFish, Bayan Lepas, Pulau Pinang, 11960, Malaysia

${ }^{\mathrm{d}}$ Food Systems Institute, University of Florida, Gainesville, FL, 32611-057, USA

${ }^{\mathrm{e}}$ Fisheries and Aquatic Sciences, School of Forest Resources and Conservation, University of Florida, Gainesville, FL, 32611-057, USA

${ }^{\mathrm{f}}$ Department of Safety, Economics and Planning, University of Stavanger, 4036, Stavanger, Norway

${ }^{g}$ Department of Agricultural, Food and Resource Economics, Michigan State University, MI, USA

${ }^{\mathrm{h}}$ National Center for Ecological Analysis and Synthesis, University of California, Santa Barbara, CA, 93101, USA

${ }^{i}$ Centre for Marine Socioecology, University of Tasmania, Hobart, Australia

${ }^{\mathrm{j}}$ Department of Ecology, Evolution and Marine Biology, University of California, Santa Barbara, CA, 93106, USA

${ }^{\mathrm{k}}$ Environmental Studies, University of California, Santa Barbara, CA, 93106, USA

${ }^{1}$ Department of Environmental Science, American University, Washington DC, 20016, USA

${ }^{\mathrm{m}}$ Lancaster Environment Centre, Lancaster University, Lancaster, LA14YW, UK

${ }^{\mathrm{n}}$ Institute of Aquaculture, University of Stirling, Stirling, FK94LA, Scotland, UK

${ }^{\circ}$ NOAA Fisheries, Northeast Fisheries Science Center, 166 Water Street, Woods Hole, MA, 02543, USA

${ }^{\mathrm{p}}$ Fisheries and Aquaculture Officer, Fisheries and Aquaculture Division, Food and Agriculture Organization of the United Nations, Rome, Italy

${ }^{\mathrm{q}}$ Urner Barry, Toms River, NJ, 08755, USA

${ }^{\mathrm{r}}$ School of Marine Sciences, University of Maine, Orono, ME, 04469, USA

${ }^{\mathrm{s}}$ School for the Environment, University of Massachusetts Boston, Boston, MA, 02125, USA

${ }^{\mathrm{t}}$ Center for Human Nutrition, Department of International Health, Johns Hopkins Bloomberg School of Public Health, Johns Hopkins University, Baltimore, MD, 21205, USA

${ }^{\mathrm{u}}$ Beijer Institute of Ecological Economics, The Royal Swedish Academy of Sciences, 104 05, Stockholm, Sweden

${ }^{v}$ Stockholm Resilience Centre, Stockholm University, 106 91, Stockholm, Sweden

${ }^{\mathrm{w}}$ College of Fisheries and Life Science, Shanghai Ocean University, Shanghai, 201306, China

\section{A R T I C L E I N F O}

\section{Keywords:}

Covid

Seafood

Nutrition

Employment

Resilience

Trade

Fish

Shocks

\begin{abstract}
A B S T R A C T
The COVID-19 pandemic and subsequent lockdowns are creating health and economic crises that threaten food and nutrition security. The seafood sector provides important sources of nutrition and employment, especially in low-income countries, and is highly globalized allowing shocks to propagate. We studied COVID-19-related disruptions, impacts, and responses to the seafood sector from January through May 2020, using a food system resilience 'action cycle' framework as a guide. We find that some supply chains, market segments, companies, small-scale actors and civil society have shown initial signs of greater resilience than others. COVID-19 has also highlighted the vulnerability of certain groups working in- or dependent on the seafood sector. We discuss early coping and adaptive responses combined with lessons from past shocks that could be considered when building resilience in the sector. We end with strategic research needs to support learning from COVID-19 impacts and responses.
\end{abstract}

\footnotetext{
* Corresponding author. Center for a Livable Future, Johns Hopkins University, Baltimore, MD, 21202, USA.

E-mail address: dlove8@jhu.edu (D.C. Love).
} 


\section{Introduction}

The COVID-19 pandemic and subsequent lockdowns are creating health and economic crises, leading to increasing incidence of poverty (Sumner et al., 2020) and a looming food crisis (Conti et al., 2020; World Food Programme, 2020). The food system has been seriously disrupted with impacts occurring at multiple levels and across supply chains (Hobbs, 2020; Global Panel, 2020; Devereux et al., 2020; Chenarides et al., 2020). Studying these impacts identifies vulnerabilities within the food system as well as opportunities for governments, international bodies, industries, small-scale actors, and civil society to respond, learn, adapt, and build resilience to future shocks. Seafood is one of the most traded food commodities, both globally (Gephart and Pace, 2015) and regionally (Belton et al., 2018), and is composed of many species and production and distribution strategies. Much can be learned about food systems in pandemics by studying COVID-19-related shocks and responses in the seafood sector.

The current pandemic began in China, the world's giant when it comes to producing, consuming, and exporting seafood (FAO, 2019). As the pandemic spreads and reemerges, a patchwork of impacts and responses are occurring across this sector and across scales. Strategies to absorb shocks, react, and restore the functions of the seafood sector are critical. For hundreds of millions of people, seafood is an integral part of their livelihood, culture, and food and nutrition security (FAO, 2018). Included in these populations are women, migrant workers, and a large informal sector (Kelleher et al., 2012) that may not benefit from pandemic aid funds from governments or financial institutions.

In order to rebuild toward a more resilient food system, it is necessary to understand the scope of recent disruptions, impacts, and range of responses. We applied a food system resilience 'action cycle' framework (Fig. 1) (Tendall et al., 2015) as informed by concepts of coping, adaptation (Lebel et al., 2006), and specified vs. general resilience
(Folke et al., 2010). We use the term resilience to mean the "capacity over time of a food system and its units at multiple levels, to provide sufficient, appropriate and accessible food to all, in the face of various and even unforeseen disturbances" (Tendall et al., 2015). Using these concepts, we ask three central questions: First, how has the seafood system been impacted by COVID-19? Second, what types of responses have occurred thus far to absorb and react to COVID-19 disruptions and what actions have been taken to restore system functions? Third, what lessons from current and past shock events can help to inform actors and institutions as they build resilience to future shocks to pandemics or other types of large-scale disturbances?

\section{Materials and methods}

\subsection{Data}

Seafood production, trade, and retail sales were collected through June 2, 2020 from national government agencies and market reporting companies. Many datasets were reviewed and analyzed, and only a handful are presented here to show examples of different types of impacts to regions, sub-sectors, and stages of the value chain. We analyzed China domestic fish sales at 147 wholesale markets (MOA, 2020) to show the early impacts of lockdowns in China. We explored shifts in trade using China imports of edible seafood, China tilapia exports by product form and region (China Customs, 2020), Ecuador shrimp exports by region (Rubio and Schreiber, 2020), Norway farmed salmon exports (Norwegian Seafood Council, 2020), and international trade data (i.e., United Nations Comtrade) (United Nations, 2017). To illustrate consumer shifts in the Global North we examined European Union seafood imports of live-fresh and frozen products, which represents $80 \%$ of total import value (European Market Observato, 2020), as well as U.S. reservation data from over 20,000 restaurants (Open Table, 2020), U.S.

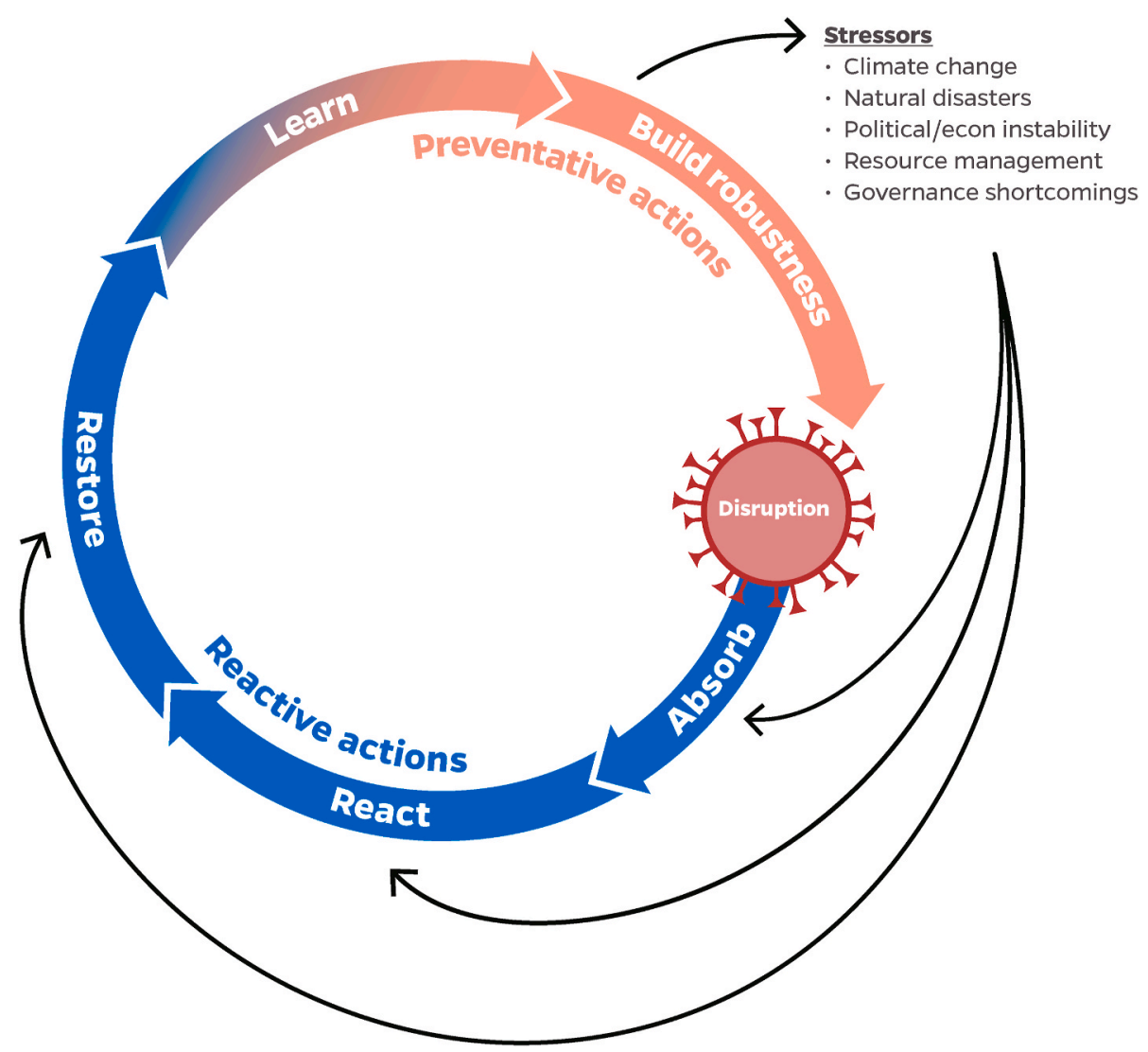

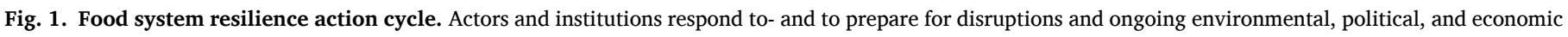
stressors using a series of reactive and preventative actions. Modified from (Tendall et al., 2015). 
Table 1

Reactive actions to COVID-19 by seafood system actors and institutions. (See Appendix Table S1 for country-specific examples and references.)

Actions by Actors and Institutions

Governments and Development Partners

Health and safety responses to protect public health, as well as safety and working conditions for fishers and fish farmers, including through the use of technologies

Social protection and employment response including non-contributory assistance programs (one-off cash transfer, food distribution), social insurance (e.g. unemployment benefits) and labor market interventions (e.g. wage subsidies) to mitigate shortterm impacts. These responses differ according to national fiscal policies.

Economic responses to provide emergency assistance including aid, reallocation of financial resources, loans and subsidies to mitigate the short-term impacts of the crisis on commercial fisheries and aquaculture. These responses have been observed in both high- and low-income countries but appear to be significantly larger in high income countries. In both, challenges have been reported in accessing funds, especially for small holders and the informal sector.

Management measures and other technical responses to respond to the impacts of COVID-19 on commercial fisheries and aquaculture Large-Scale Commercial Fisheries and Aquaculture

Health and safety responses to ensure the health and safety of workers along the supply chain as well as social support to national efforts

Social protection and industry responses, including advocating for and pursuing social protections and reducing workforce in response to diminished demand and/or changes in the marketplace

Economic responses targeting retail and consumer markets, including online and home delivery

Small-Scale Sector and Non-Governmental Organizations

- Health and safety responses, including arrangements and information to support and strengthen communities and vulnerable populations

Social protection and sector responses, including collective action and networking within or across small-scale fishing sector as well as fish workers and small fish farmers to maintain safe employment opportunities

Economic responses via local and seafood direct marketing Consumers

Shift in consumer purchasing as a result of the pandemic with uncertainty about the future

retail food sales (Nielsen, 2020), and U.S. national food expenditures by food source (USDA, 2020). These data include the volume and/or value of seafood published on a weekly or monthly basis for the period of January 1, 2018 through April 30, 2020. Given the early stage of the pandemic at the time of the analysis, some trade datasets and national-level data, particularly in low- and middle-income countries, were incomplete or not available. Year-over-year percent change was calculated as the current trade volume (for a week or a month) minus the previous year's volume divided by the previous year's volume times 100. Prices were converted to U.S. dollars per $\mathrm{kg}$ and calculated as the total value divided by the total volume for a time period.

To complement the sales datasets reported above, we collected news articles $(\mathrm{n}=175)$ published from January 28 to May 27, 2020 and analyzed reported impacts and responses on the seafood sector. News articles were collected from April 3 to May 30, 2020 by monitoring Google News alerts for ("seafood" OR "fish") AND ("COVID-19" OR "covid"), daily data scraping of Twitter posts for "seafood" and "COVID19 " OR "covid," website searches of primary seafood industry news outlets (e.g., Seafood Source, Undercurrent, and IntraFish), and compiling information shared through the authors' professional networks. All news articles containing information about an impact from or response to the COVID-19 pandemic relating to any stage of the seafood supply chain were considered relevant. For each post, we extracted information on the date of the article, date of the reported impact, the type of impact, reported countries, sector(s), supply chain stage(s), species/ taxa, and product form(s) involved. The extracted data and links to original news articles are available through the COVID-19 Seafood Impacts database (Gephart et al., 2020). While this database is not intended to represent a complete accounting of all impacts and responses, it does represent a sampling of the early impacts and responses across small-scale and industrial production, wild-capture and aquaculture systems, all supply chain stages, and over 40 high- and low-income countries/territories.

Examples of responses were drawn from the database (Gephart et al., 2020) as well as emerging policy statements and technical reports published by governments and development partners during our study period to create Table 1 and Supporting Information Table S1. Utilizing these latter sources, enabled us to rapidly evaluate early responses and strategies around the world and across sectors in the seafood supply chain. Responses and strategies were inventoried and then organized thematically using an iterative and inductive approach as new information became available.

\subsection{Terms and definitions}

We distinguish between specified resilience (specific to one type of shock) and general resilience to a range of shocks and stressors (e.g., economic, political, climatic, or biotic) (Folke et al., 2010). For either dimension, 'building resilience' can be an explicit goal of seafood system governance in the future. When considering responses to shocks, we refer to coping as short-term reactive measures that cannot be sustained for long periods and adapting as longer-term and planned change in practices (Lebel et al., 2006).

\section{Results and discussion}

\subsection{General disruptions from COVID-19 to the seafood system}

Published data across news, social media outlets, governments, and development partners provide an emergent picture of disruptions or shocks to multiple stages of supply chains (Fig. 2). These disruptions caused a generalizable range of impacts across different subsectors, product forms, markets, and consumer segments. Impacts from the pandemic were felt first in China and among its trading partners (Fig. 3), but quickly spread around the world. In some cases, disruptions occurred simultaneously to multiple stages of a supply chain. In other cases, the impacts propagated out as a pressure wave ahead of COVID-19 cases, causing second order impacts following shifts in trade. We also expect lagged impacts caused by high uncertainty about future demand or disruptions to production inputs that take longer to be realized. Disruptions in some regions or sectors are magnified by existing stressors such as climate change, natural hazards (Pacific cyclone season, African locust season), resource management, and political or economic instability. Below we use data to discuss specific disruptions to seafood demand, distribution, labor, and production.

\subsubsection{Demand disruptions}

The first demand impacts were experienced in China in late January and early February 2020, as lockdowns caused domestic seafood trade to drop precipitously with high-value marine fish species sold at restaurants more impacted than lower value farmed carp sold at retail outlets (Fig. 4a). Lower consumer demand in China led to reduced import volumes, however, as the pandemic subsided within China, seafood imports and domestic carp sales rebounded, but sales of high-value marine fish to restaurants have not rebounded (Fig. 4a and b). In high-income countries, such as the United States (U.S.) there was a dramatic shift in all food sourcing favoring eating at home over restaurants due to public health measures to reduce COVID-19 spread (Fig. 4c). This shift in food sourcing is reflected by more online searches for terms "seafood recipes" and "seafood delivery" in the U.S. compared to the previous four years (White et al., 2020). As restaurants typically 


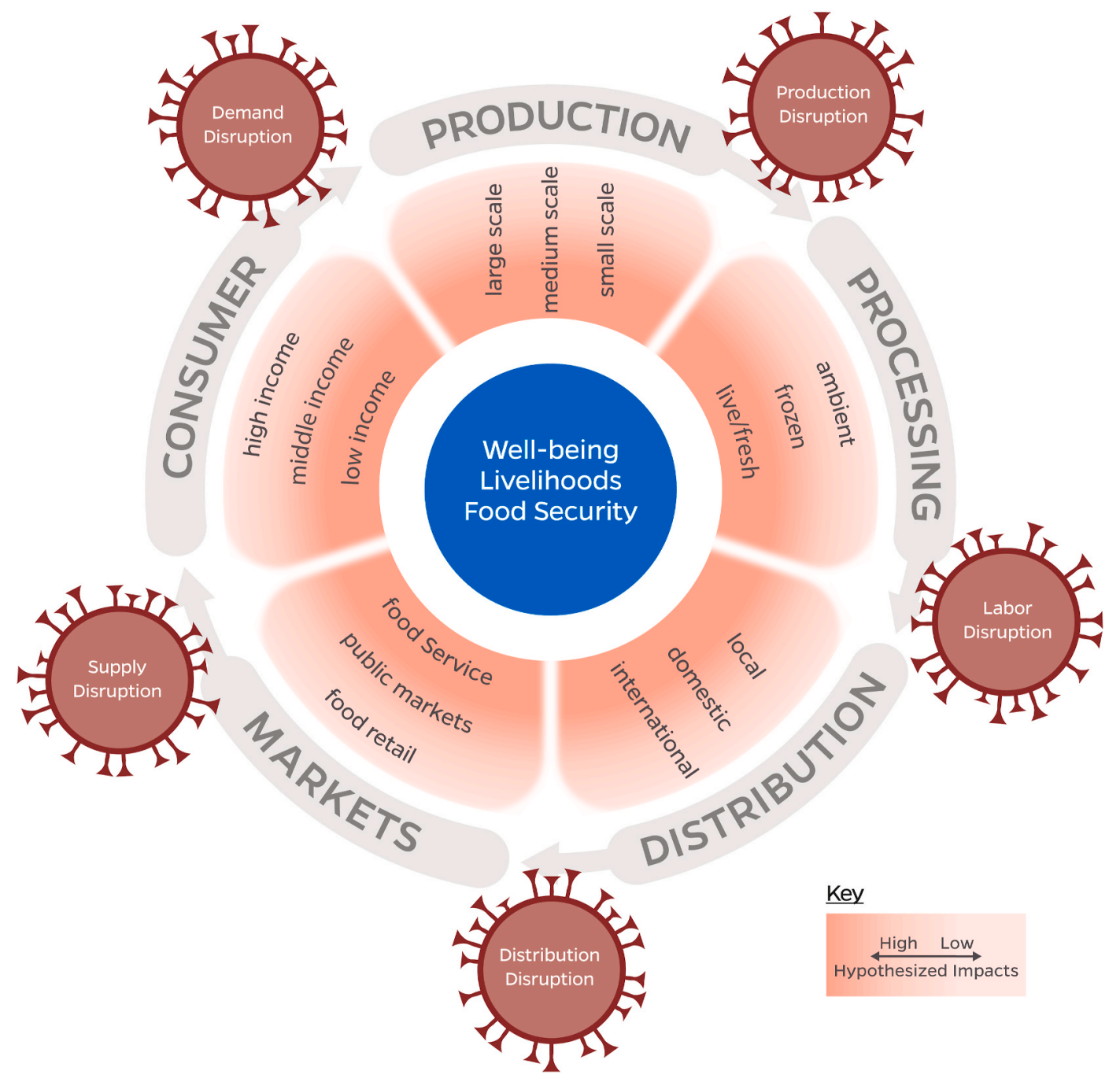

Fig. 2. COVID-19 disruptions and impacts on seafood supply chains. Disruptions to production, labor, distribution, supply and demand create a range of impacts. The color gradient indicates the hypothesized relative impacts to different components of- or actors within seafood supply chains. The ordering of groups is based on multiple data streams collected through May 2020 but is not intended to be a quantitative or absolute ranking. In the center of the figure are key outcomes: human well-being, livelihoods, and food security.

sell more expensive live and fresh seafood, restaurant closures constrained markets for these products. In the European Union, lower demand at restaurants led to a $30 \%$ drop in imported live-fresh seafood prices (Fig. 4d).

In low-income food-deficit countries, such as Ethiopia, public health interventions reduced household incomes, which translated into reduced expenditures on nutrient dense foods that, if sustained, could lead to malnutrition (Hivrvonen et al., 2020). In Yemen, where seafood plays a bigger role in diets and economies, there has been a coincidence of war, climate change, and now COVID-19, which has led to famine (na, 2020a). As COVID-19 spreads, poverty and hunger will continue to be concerns in low- and middle-income countries (LMICs) (Laborde et al., 2020).

\subsubsection{Distribution disruptions}

Seafood trade was disrupted, redirected, or halted by sudden shifts in demand, supply, and limits on the movement of goods and people. Many of the earliest trade impacts radiated from China (Fig. 3). In January 2020, China banned imports of live animals which impacted trade of e.g. live lobsters from many countries (Fig. 3). Some ports were closed for quarantine, which forced cargo ships to reroute and increased congestion at other ports, or shipments were cancelled entirely (Mereghetti, 2020). Cancelled international passenger flights created logistical problems and increased air freight costs for high-value seafood products such as farmed Atlantic salmon (Huffman, 2020). Cancelled shipments left producers and distributors without a market for perishable products or with a shortage of freezer space. In some cases, distributors were able to shift trade to other markets showing signs of greater resilience. For example, frozen Ecuadorian shrimp was re-routed from China to the U.S. and Europe in January through March 2020, and then back to China in April 2020 (Fig. 4e). Norwegian salmon was redirected from China to other countries such as the U.S. and Brazil (Seaman and Harkell, 2020), without a significant change in volume or price (Fig. $4 \mathrm{f}$ ). As consumers began eating more at home, China dramatically increased their exports of processed tilapia, which are breaded or spiced fillets that are easy to cook at home (Fig. $4 \mathrm{~g}$ and $\mathrm{h}$ ).

Trade disruptions have secondary impacts on LMICs. For example, the diversion of China's farmed tilapia to North America (Fig. 4h) corresponded with a drop in exports to some countries, notably a 50\% drop in exports to some developing countries in April 2020. The drop in Chinese tilapia initially opened up markets to local fishers around Lake Victoria (Standard Team, 2020), however, this short-term benefit was dampened as the Kenyan government introduced curfews to control the spread of COVID-19. Curfews decreased night-fishing activity for both expensive export products (e.g., Nile Perch) and affordable nutritious small fish for local consumption (e.g., Dagaa) (Kolding et al., 2019), 


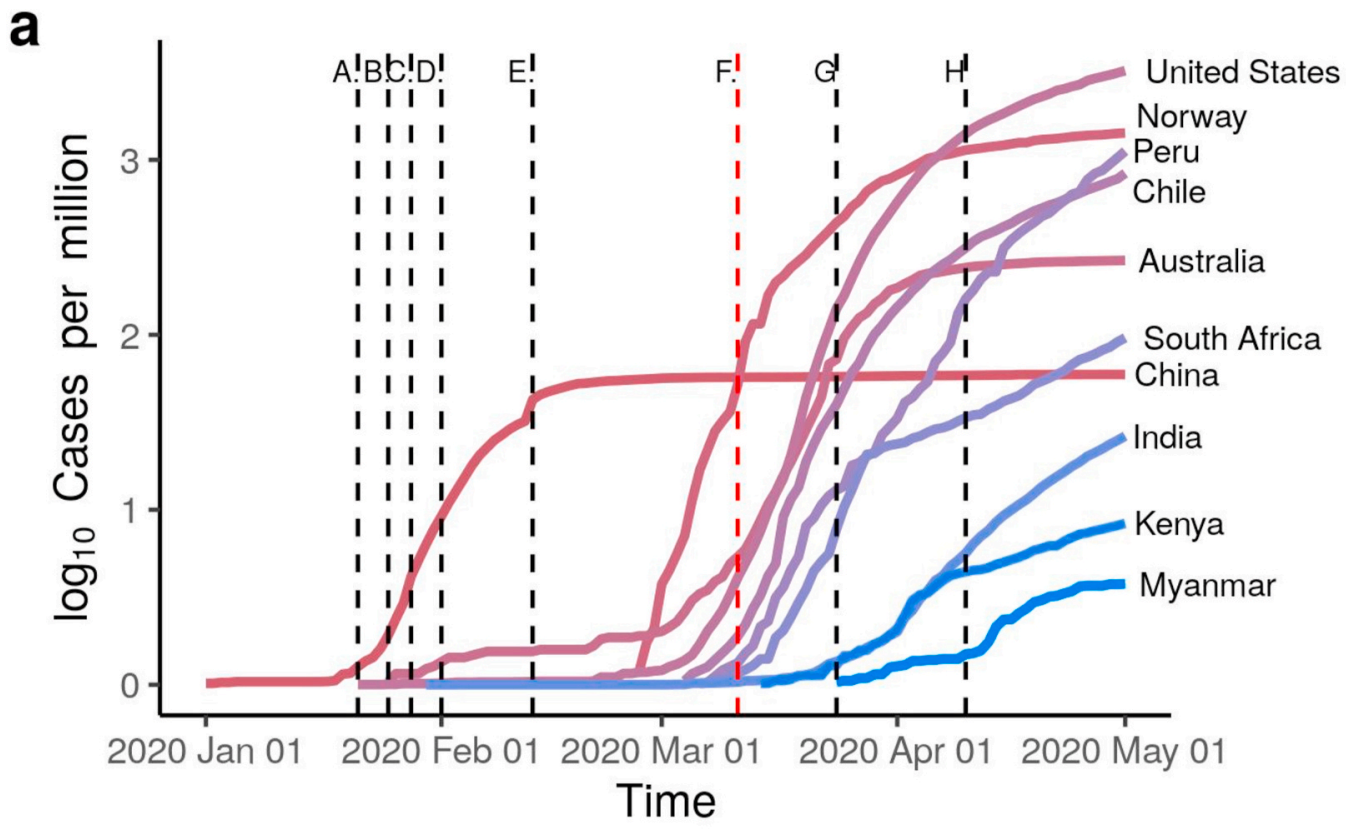

b
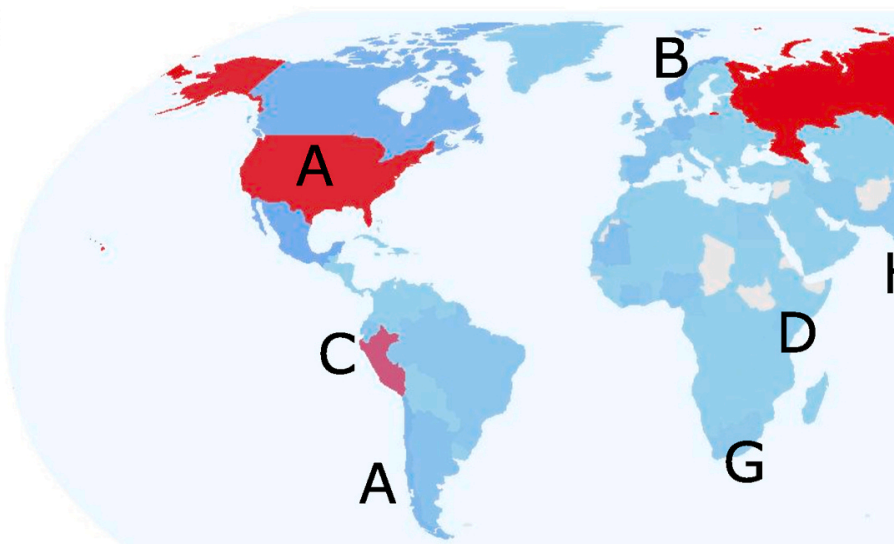

Total seafood trade with China (MMT)

$\begin{array}{llll}0.25 & 0.5 & 0.75 & 1\end{array}$
A Wild lobster, farmed salmon, geoduck exports cease
B Farmed salmon exports to China cancelled
C Cancelled exports continue. Chinese freezers full, ships re-routed
D Imports of Chinese tilapia slow
E Chinese aquaculture exports struggling with border and labor restrictions
F World Health Organisation declare COVID-19 a pandemic
$\mathrm{G}$ Lobster fishery closed due to cancelled exports to China
$\mathrm{H}$ Slow recovery of exports of farmed shrimp to China and US

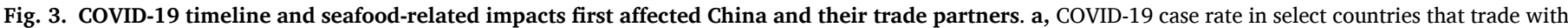

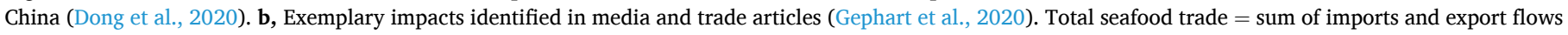
with China.

which along with trade shifts, increased price volatility (Ramsdan, 2020). Tilapia farms on Lake Victoria suffered disrupted feed supplies and responded to increased demand for smaller fish and expanded market opportunities outside of the capital.

As countries increase screening for COVID-19, trade disruptions will continue pending positive detection. China has recently halted seafood trade with Brazil, Chile, Ecuador, Indonesia, India, the Netherlands, and Russia after finding COVID-19 on packaging. While the likelihood of virus transmission to humans through food is low (Rizou et al., 2020), a risk-averse approach to food safety will result in overly cautious rejection of suspect products. 

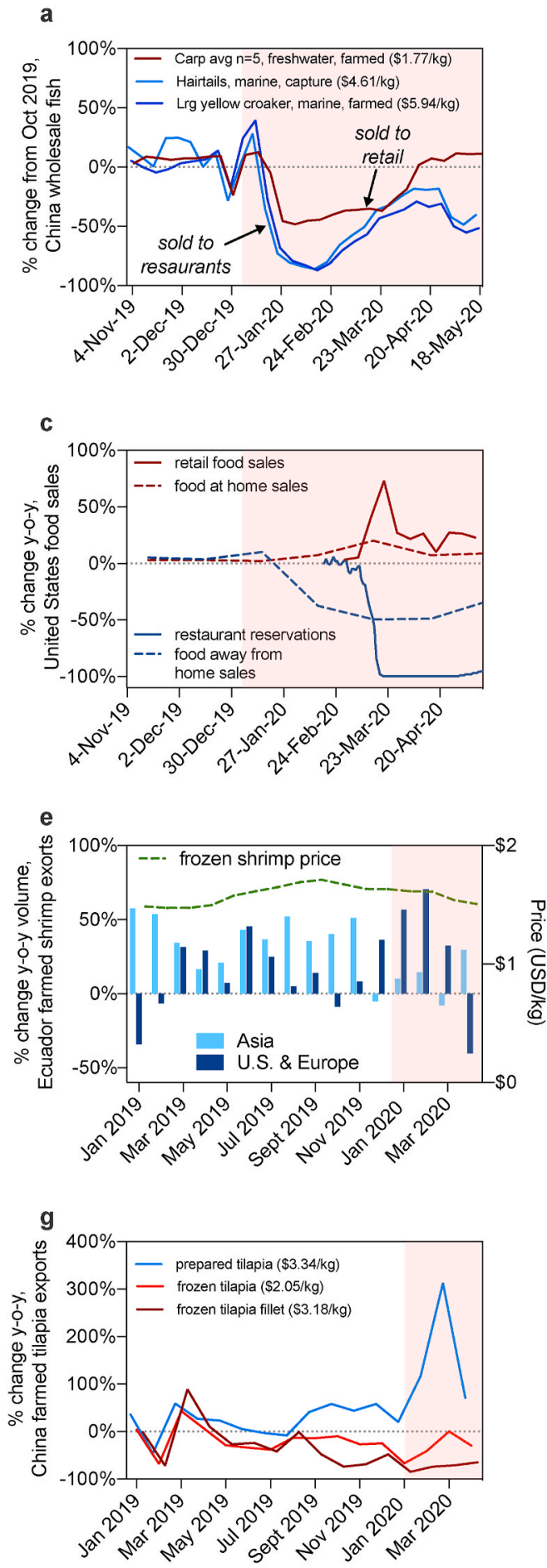

b

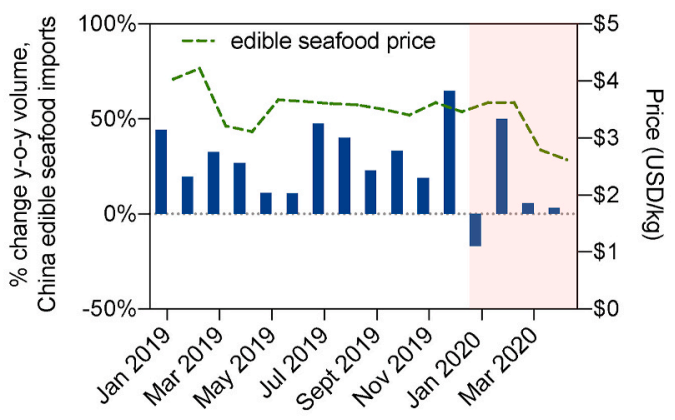

d
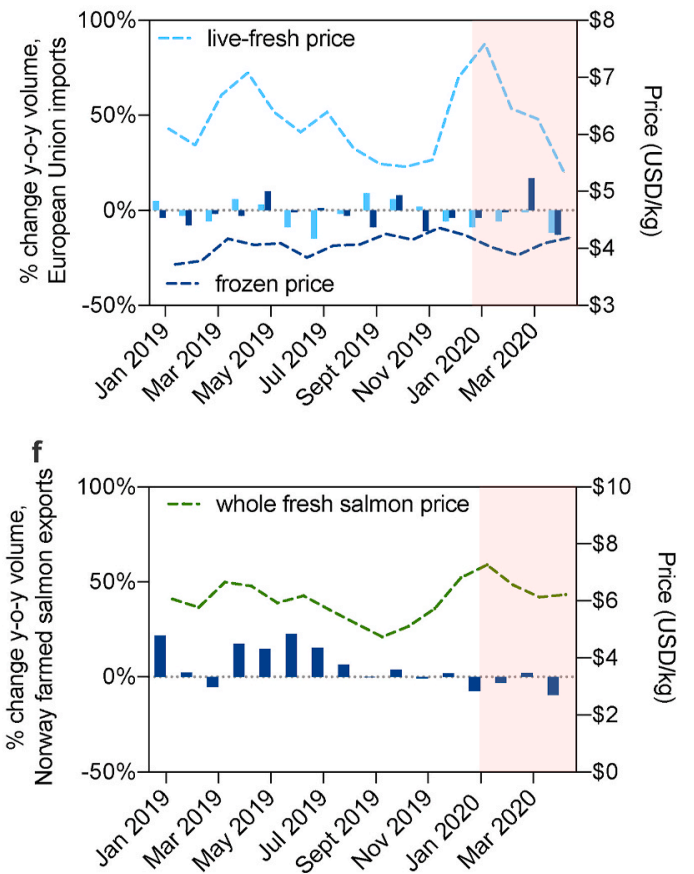

h

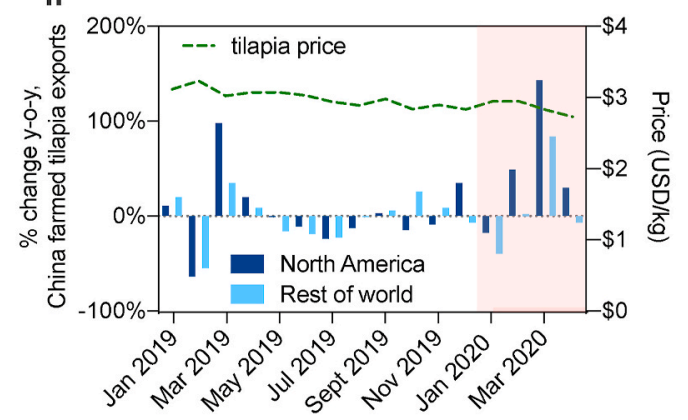

Fig. 4. COVID-19 impacts on seafood production, trade, and wholesale and retail sales through April 2020. a, China domestic fish sales volume at 147 domestic wholesale markets using an index of key species. b. China edible seafood imports. c, United States all food sales by food source using two nationally representative datasets and reservations at $>20,000$ restaurants. d, European Union seafood imports of live/fresh and frozen products using aggregate product forms representing $80 \%$ of the total value of imports. e, Ecuador farmed shrimp (36-40 ct, shell on) exports by region. f, Norway farmed Atlantic salmon exports (fresh, whole fish). $\mathbf{g}$, China tilapia global exports by product form. $\mathbf{h}$, China tilapia exports to North America and the rest of the world. The percent of exports by region in 2017 and 2018 was as follows: North America (51\%), Africa (30\%), Asia (10\%), Europe (7\%), and South America (2\%). References provided in the methods section. Pink indicates the time period of COVID-19.

\subsubsection{Labor disruptions}

Lockdowns disrupted employment in seafood supply chains for workers, and access to labor for seafood businesses. In many low-income food deficit countries, farms and enterprises in food supply chains provide self-employment and casual work for many people. COVID-19 policy responses impacted the operation of such businesses resulted in lowered incomes and caused substantial unemployment (Reardon et al., 2020; Liverpool-Tasie, Reardon, Belton). Migrant fish workers were not able to leave fishing boats in India, ports in Thailand, or an Ecuadorian fishing vessel in the South Pacific, and closures of fish markets have 
rendered many fish workers jobless (Marschke et al., 2020; Havice et al., 2020; WorldFish, 2020). India's nationwide lockdown also forced the closure of hatcheries, feed mills and processing plants, and sharp drop in demand from the U.S. and Europe reduced international exports of frozen shrimp, which account for $70 \%$ of India seafood exports. Similar impacts have been reported in Bangladesh and Myanmar (WorldFish, 2020; Mamun et al., 2020). COVID-19 outbreaks have occurred among seafood process workers in Ghana (Reuters, 2020), the U.S. (Bernton, 2020), and elsewhere, as well as other animal processing plants (Center for a Livable Future, 2020).

\subsubsection{Production disruptions}

Seafood production decreases have sometimes occurred in parallel with COVID-19 cases and at other times lagged reductions in consumer demand. COVID-19-related lockdowns have decreased industrial fishing efforts in China, Spain, France, and Italy by $40 \%$ to $>50 \%$ in the first quarter of 2020 compared to 2019 (Clavelle, 2020). Reductions in Pacific tuna fishing are due to port closures and a lack of fisheries observers, while coastal subsistence fishing has increased (na, 2020b). Alaskan fishing and processing vessels experienced outbreaks at sea, and the Alaskan sockeye salmon fishery, which is highly dependent on seasonal workers, saw a $50 \%$ reduction in price due to disruptions in trade, air freight, and lower demand for fresh fish (White, 2020).

Aquaculture production has been disrupted as farmers contemplate whether to restock given uncertainty over demand. For example, in April 2020, shrimp farmers across Southeast Asia stopped stocking ponds (Dao, 2020), in some cases due to difficulty importing broodstock, which will produce lagged reductions in supply (UN FAO, 2020). Species with long grow-out periods, such as shellfish and salmon, can be held in the water until markets improve, but not indefinitely and not without economic costs. This range of impacts across the supply chain has been met with diverse responses deployed by governments, the seafood industry, and consumers.

\subsection{Reactive actions to COVID-19 by seafood system actors and institutions}

We explore the reactivity of multiple actors and institutions in response to COVID-19 through May 2020. These include initial steps to absorb and react to disruptions, and to restore functions to the seafood system (Fig. 1). We categorized these actions as short-term coping and forward-looking adaptive responses. At the time of writing, responses were mostly aimed to: 1 ) protect public health, including the health of fishery sector workers; 2) support those whose enterprises, jobs, and incomes are affected by COVID-19 related disruptions; and 3) maintain seafood supplies to consumers. Initial coping responses, in particular by governments, sought to maintain the sector's core functions through the period of wide-spread economic disruption, while protecting the most vulnerable. Longer-term adaptive measures, that often emerge outside of government, can contribute to building COVID-19-specific and generalized resilience to multiple shocks and stressors. Below we discuss specific responses by different actors and institutions which is summarized in Table 1 and Appendix Table S1 with expanded country-specific examples.

\subsubsection{Governments and development partners}

Government responses have exposed deep tensions between protecting public health and preventing an economic crisis (Appendix Table S1). This is reflected in short-term coping strategies to address immediate challenges posed by the crisis. For example, early on, many governments, including those in Russia, Canada, and South Africa (Seaman, 2020; na, 2020c; Oirere, 2020), designated fishers, fish farmers, and fish processors as "essential workers" allowing them to operate in order to maintain the food supply. Along with these actions, protective measures were taken to safeguard worker health (Table 1). These were coupled with social protections to lessen the socioeconomic toll of the pandemic and keep companies going, with efforts to distribute the funds equitably varying in their levels of success (Bloom, 2020; Low Impact Fisheries of Europe, 2020).

Development partners including non-governmental organizations (NGOs) have also acted to support governments in dealing with the immediate impacts of COVID-19. Their actions comprise adaptive responses that can form the basis for building resilience. They targeted countries and regions where governments had limited capacity to implement social and economic measures seen elsewhere. For example, the United Nations Food and Agriculture Organization and WorldFish are providing policy recommendations, technical advice, and support and/or harnessing research to guide government responses (WorldFish, 2020; FAO, 2020). The World Bank is providing grants and loans to countries to assess impacts and develop responses.

\subsubsection{Large-scale commercial sector responses}

Responses to the pandemic from the industrialized sector have been swift, detecting early signs of weaknesses in global seafood markets and making resources available to rapidly adjust marketing and distribution. Early coping responses focused on protecting worker health, consumer health, and securing production and supply chains during the pandemic (Appendix Table S1). Nevertheless, some seafood workers remained exposed to outbreaks (Reuters, 2020; Bernton, 2020). The economic response has included reducing the size of workforces to lower expenditures, but some companies have also responded by shifting into or strengthening their positions in retail and online markets, where consumer demand has been high; the ability to make such transitions could represent longer-term adaptation. Companies selling frozen and shelf-stable products as well as companies with strong relationships with retailers have been particularly well positioned to adapt sales from the restaurant sector to retail markets. The use of technology, such as online sales, has allowed companies to promote and market their products and connect with consumers (Appendix Table S1). However, reliance on technology as a solution to the crisis opens the potential for increasing inequity across seafood value chains, as these tools are not available to everybody.

\subsubsection{Small scale-sector and non-governmental organization responses}

Small-scale fisher responses to the pandemic have predominantly comprised actions that can translate into longer-term adaptive strategies that build resilience. Early on, some small-scale fish worker networks, which are often global with strongholds in LMICs such as India or South Africa, mobilized to share information, document impacts, and advocate for government resources (The International Collective in Support of Fishworkers, 2020). Others formulated recommendations to fight against COVID-19 and improve the working conditions of artisanal fisheries with a specific focus on women (Coalition for Fair Fisheries Arrangements, 2020), who represent a large share of the total workforce (Kleiber et al., 2015). In some cases, producer organizations have bought back fish from their members by applying the withdrawal price - a minimum price guaranteed throughout the year even in the absence of demand. Artisanal fishers and small holders have also turned to food banks and other forms of food sharing to distribute the catch (McVeigh, 2020; Bennett et al., 2020). Some NGOs are working with local fishers and women fish workers to connect catch to private households to support direct marketing of catches that would otherwise go unsold. There has also been a surge in direct producer-to-consumer sales (Stoll et al., 2020). For example, user traffic on the Local Catch Network in the U.S. was up by $310 \%$ from March 15, 2020 to May 14, 2020 compared to the previous year.

\subsubsection{Consumer responses}

Consumer response has been largely conditioned by public health measures that have confined people to their homes. Early responses included panic buying, a shift from restaurants to retail purchases and home delivery and local seafood purchasing (Xia, 2020). Consumers in 
high-income countries have focused on buying seafood products with longer shelf-life and frozen products, while in low-income food-deficit countries there are early examples of reduced household income leading to shifts towards staple foods and away from nutrient dense foods like fish (Hivrvonen et al., 2020). There has also been some concern about the safety of seafood as SARS-CoV-2 has been detected on seafood packaging in China (Liu et al., 2020), however, the most common route of transmission is respiratory from person to person (Vella et al., 2020).

\subsection{Learning and building resilience to future shocks}

COVID-19 has exposed vulnerabilities and power imbalances in the food system, as well as highlighted broader inequalities and health disparities across society (Ahmed et al., 2020; Hooper et al., 2020). Coping and adaptive measures represent early responses during the first five months of the COVID-19 pandemic. Others have identified adaptations such as switching species harvested, selling to alternate markets, supplementing income from other sources, or temporarily stop fishing (Smith et al., 2020). Short-term coping will remain important as the pandemic spreads and re-emerges in countries. Actors and institutions within the seafood sector can carry adaptive responses forward and engage in a process of learning and building robustness to prevent future shocks (Fig. 1). Based on the literature and findings from this study, we provide three key concepts to guide this 'adaptive cycle' process.

\subsubsection{Identify resilience, vulnerability, and power imbalances in seafood} systems

The seafood system is a meshed network of formal and informal producers and distributors, retailers, and consumers. Some supply chains, market segments, companies, small-scale actors and civil society have shown initial signs of greater resilience than others. In high-income countries, food retailers and supply chains selling shelf-stable and frozen seafood have done well following COVID-19-related shifts in food sourcing, while live-fresh and high-value producers selling to restaurants were particularly hard hit. A surge in direct producer-to-consumer sales in the U.S. may foretell a longer-term shift in consumer purchasing habits. Conversely, in many LMICs, such as India, the informal sector was particularly hard hit by restrictive government responses to the crisis that prevented many actors from engaging in their livelihood activities (Balasubramanian and Samuel, 2020), which could lead to less household income and decreased food security.

Maintaining and building diversity and connectivity at the community, company, and country level are ways to build resilience and guard against bad outcomes. Communities with diverse networks, such as in Mexico, were able to mobilize for support in the form of food aid and relief (Ramirez, 2020). Strengthening local food systems, for example in India, is another way to build resilience in communities (Pothan et al., 2020). Companies with diverse portfolios and connections to more markets could more easily switch between commodities or divert products at a global scale (e.g. Ecuadorian shrimp, Chinese tilapia) thus enabling them to continue their business. Diversity and connectivity to markets at the country-level enables continuous supply of seafood.

Many countries, however, are increasingly reliant on food imports from a shrinking number of exporters (Kummu et al., 2020), which makes them more vulnerable to disruptions. The tendency towards concentration in the seafood sector creates power imbalances that risk undermining food security in low-income countries and communities (Österblom et al., 2015). Companies and countries that were able to diversify and adapt did so, in some cases, by exposing other aspects of the global system (e.g., low-value markets in low-income food-deficit countries) to trade shocks. Efforts to build resilience following COVID-19 should consider resilience to what?, for whom?, and for what purpose? (Lebel et al., 2006), and be attentive to the possibility of propagated impacts from these decisions.

\subsubsection{Transition from short-term coping to longer-term adaptation}

As the pandemic shifts and reemerges in countries, there will be continuing need for coping responses to maintain the sector's core functions and protect vulnerable populations working in- or dependent on the seafood sector. Some coping responses, such as removing normal restrictions on fishing or increasing fishing quotas, which result in overharvesting, may be maladaptive or have unintended consequences that undermine the resilience of the seafood system in the long-term. Responses will vary across regions and countries reflecting the different levels of economic, social, and political capital available to address the impacts across sectors in the seafood system, as well as the nature of the labor market. Informally employed workers, many of whom are women and migrants and are especially prevalent in Asia and Africa, are often omitted from social protection schemes and other entitlements.

While short-term coping strategies will remain important for some time, it will be critical for actors and institutions to transition to the preventative phase of the resilience 'action cycle.' This phase includes starting the learning process and developing and implementing longerterm adaptation strategies and resilience building, which is necessary to prevent impacts of future shocks and respond to ongoing stressors such as climate change or political instability. These shifts will be staggered in time as actors move beyond the reactive phase and the pandemic progresses through countries and regions of the world. An additional consideration is how specialized adaptations should be as increasing resilience of the seafood sector to future pandemics may reduce general resilience to an unknown array of future shocks (Folke et al., 2010). Lastly, the United Nations recommends using the COVID-19 shock as an opportunity to transform the food system to be more green, inclusive, and resilient (United Nations, 2020a, 2020b). The idea of shocks as "windows of opportunity" to engage in transformations is a key feature of resilience thinking (Folke et al., 2010). The current seafood system does not work for all people; it falls short in addressing concerns over environmental sustainability (Troell et al., 2014), social equity (Kittinger et al., 2017), and nutrition security (Hicks et al., 2019). Returning to business as usual following this shock would be missing an opportunity to build forward better.

\subsubsection{Avoid mistakes of past responses}

While COVID-19 presents a significant shock to the seafood sector in terms of magnitude, extent of supply chain influence, and global scope, previous shocks offer useful lessons (Davis et al., 2020). Three key lessons relate to trade restrictions, overstimulating production, and food prices and aid.

First, to avoid propagating shocks through trade, as occurred in the 2008 grain crisis, countries should maintain food supply buffers and cooperate internationally to avoid export bans and hoarding behavior (Seekell et al., 2017; Marchand et al., 2016; Gephart et al., 2016). As of mid-April, 20 countries representing $5 \%$ of the global calorie market had implemented restrictions on food exports, mainly for cereals and grains, and limited restrictions on animal products (eggs, chickens) (LabordeDebucquet, 2020). While these actions have seemingly not triggered a cascading crisis, seafood flows were disrupted with impacts worse in some areas than others, and additional stressors such as associated economic recessions and future waves of COVID-19 could worsen the situation.

Second, surges in fishing effort in Europe after WWII (Holm, 2012) or more recently in Sri Lanka following the 2004 tsunami (De Silva and Yamao, 2007) led to overfishing. As governments and industries try to reboot the economy in the coming period, there is a risk of overstimulating production in some regions and fisheries, which could harm fish populations and the marine environment. Related to overfishing is the need to continue tracking lapses in monitoring, enforcement, and observers aboard vessels as they could lead to illegal, unreported, and unregulated (IUU) fishing and subsequent environmental impacts (Bennett et al., 2020). This underscores the essential work of onboard observers who continue to work under difficult conditions throughout 
Table 2

Short-term and longer-term strategic research needs to support learning from COVID-19 impacts and responses.

Strategic research needs

Immediate research needs:

- To complement price and production data, use survey tools to document and better understand COVID-19 impacts on people working at all levels in seafood value chains and seafood consumers in order to direct support to vulnerable actors in the seafood system. Examples of this work include: (Smith et al., 2020; Rosen, 2020; van Senten; Kumaran et al., 2020; Campbell et al., 2020; Seshagiri et al. et al.; Giannakis et al., 2020; Steenbergen et al., 2020; Sorensen et al., 2020)

- Document and share case-experiences of actors in the value chain that have adapted to shifts in supply and demand of seafood so lessons from their strategies can be more widely adopted. Examples of this work include: (Stoll et al., 2020; Smith et al., 2020)

- Improve open data and data sharing platforms to facilitate the exchange of information about the societal impacts of COVID-19, to enable more rapid and coordinated responses to future shocks. Other fields are also calling for data sharing to respond to COVID-19 (Moorthy et al., 2020; Oliver et al., 2020; Foraker et al., 2020)

Longer-term research needs:

- To design future response strategies in support of the 'tropical majority' of smallscale fish producers and traders, draw on lessons from social safety net programs in other food sectors, and experience with implementing the Human Right to Food

- Improve information systems to track fish prices and trade volumes typically consumed by different types of consumers (particularly in LMICs) to reduce wasted fish and enable value chains to respond to consumers' nutrition needs and demand preferences. This may include full traceability of species and stocks based on molecular/DNA analysis.

- Focus resilience research on those parts of the aquaculture and fisheries system that supply populations most nutritionally dependent on seafood and those which, through employment, support food security of low-income value chain actors.

- Develop and apply an evaluation framework and resilience indicators for seafood value chains, that include social economic and environmental aspects, to identify and learn from resilience 'hot-spots'

- Study temporal effects of the shock on employment in the sector, on migration, on adoption of technologies for production and processing, to better design future crisis-coping strategies and recovery efforts

- Study immediate and longer-term impacts on natural resource systems to identify means to sustain resources during and after future system shocks

- Understand how the fisheries and aquaculture sectors may or may not be different from other food sectors from a resilience perspective for COVID-19 and other largescale disturbances.

the pandemic.

Third, during past shocks, the quality of the diet often suffers as families shift purchasing behavior to less expensive staple foods. For example, during the 1997 to 1998 Asian financial crisis in Indonesia, households were largely able to maintain calorie intake, but anemia rates rose following decreased consumption of micronutrient rich foods (e.g., eggs, meat, fish) due to high prices (Klotz et al., 2008). This is confirmed in Bangladesh, where maintaining low staple food prices can benefit lower income consumers by freeing up money to access fish and other pricier foods (Torlesse et al., 2003). It is estimated that the COVID-19 pandemic could double the number of people who are acutely hungry, from 130 million currently to 265 million (World Food Programme, 2020). Understanding the complex interplay between household income, food prices, and access for staple foods and micronutrient dense foods (including fish) can help governments and institutions better respond to current and future shocks.

\section{Conclusion}

This paper describes disruptions to- and responses by actors at multiple levels in the seafood system to fast moving, continually evolving shocks that have a direct impact on livelihoods, economies, food and nutrition security. We use a resilience 'action cycle' framework to study the first five months of COVID-19-related disruptions, impacts, and responses to the seafood sector. This framework helps actors and institutions contextualize their responses to the current shock, and learn, adapt, and prepare for future shocks. As the pandemic continues to threaten public health and economies there is much we need to learn. We propose a series of immediate and longer-term research needs to guide strategic research investments, and show examples of new studies that fill proposed research gaps (Table 2). COVID-19 has also highlighted the vulnerability of certain groups working in- or dependent on the seafood sector. Early coping and adaptive responses, combined with lessons from past shocks, can help inform steps to build resilience in the sector.

\section{Author contributions}

DC Love, EMN, JSS, PPdS developed the initial concept. DC Love and JAG wrote the abstract. DC Love and EHA wrote the introduction. RSC and DC Love led the section on COVID-19 disruptions with writing as review by MT, JAG, HA, AR, JSS, FP, MFT, and MT. JSS and FP led the section on reactive actions with writing as review by HF, EHA, CH, PPdS, FP, MT, and ALTL. EHA led the section on learning and building resilience with writing as review by JAG, RSC, MFT, FP, CS, PPsD, MT, and DC Love. JSS, FP, CH and ALTL created Table 1. DC Little and ALTL created Table 2. EHA and DC Love created Fig. 1. MFT, MT, DC Little, DC Love, JAG, and EHA created Fig. 2. RSC, JAG, HEF, EMN, and JSS created Fig. 3 and collected data and reviewed media publications/impacts for Fig. 3 and Table 1. DC Love, FA, BB, DC Little, AR, and WE created Fig. 4. All authors contributed to the study design and reviewed the manuscript.

\section{Declaration of competing interest}

The authors declare the following competing financial interests or personal relationships that could have appeared to influence the work reported in this paper. HEF serves on the Technical Advisory Group for Aquaculture Stewardship Council. JAG is a member of the Oceana Science Advisory Board. DC Little is a Member, Standards Oversight Committee for Global Aquaculture Association, Director Nam Sai, Thailand. JSS owns and operates a small-scale oyster farm; coordinates Local Catch Network. MFT is on the Scientific and Nutritional Advisory Council for Seafood Nutrition Partnership, the Standards Oversight Committee for Global Aquaculture Association, and a judge for Future of Fish Feed Challenge.

\section{Acknowledgements}

The CGIAR Research Program on Fish Agri-Food Systems (FISH) (for BB and EHA), and, also for EHA, Nippon Foundation Ocean Nexus program. DC Love, EMN, ALTL acknowledges funding from Johns Hopkins Center for a Livable Future (JHU) via the Santa Barbara Foundation. ALTL acknowledges funding from the Feed the Future Innovation Lab for Nutrition [USAID Cooperative Agreement No. AIDOAA-L-10-00005]. RSC acknowledges funding from the National Center for Ecological Analysis and Synthesis, University of California, Santa Barbara. HEF acknowledges support from the University of California, Santa Barbara. MT acknowledge SEAWIN project funded by Formas (2016-00227). CH acknowledges ERC grant number: 759457.

We thank Rahul Agrawal Bejarano (U Michigan), Ruth Young (JHU), and Eric Hofmeister (JHU) for assistance documenting news articles. We thank Mike Milli (JHU) for assistance with graphic design. We thank the EU Market Observatory for Fisheries and Aquaculture, Janice Schreiber, Urner Barry, and the Norwegian Seafood Council for kindly sharing seafood trade data.

The scientific results and conclusions, as well as any views or opinions expressed herein, are those of the author(s) and do not necessarily reflect those of NOAA or the Department of Commerce. 


\section{Appendix A. Supplementary data}

Supplementary data to this article can be found online at https://doi. org/10.1016/j.gfs.2021.100494.

\section{References}

Ahmed, F., Ahmed, Ne, Pissarides, C., Stiglitz, J., 2020. Why inequality could spread COVID-19. Lancent Public Health 5 (5), e240.

Balasubramanian, S., Samuel, J., 2020. Coronavirus Lockdown Adds to Woes of ClimateHit Fishers. India Climate Dialogue.

Belton, B., Bush, S.R., Little, D.C., 2018. Not just for the wealthy: rethinking farmed fish consumption in the Global South. Global Food Security 16, 85-92.

Bennett, N.J., Finkbeiner, E.M., Ban, N.C., Belhabib, D., Jupiter, S.D., Kittinger, J.N., et al., 2020. The COVID-19 pandemic, small-scale fisheries and coastal fishing communities. Coast. Manag. https://doi.org/10.1080/08920753.2020.1766937.

Bernton, H., 2020. Coronavirus Outbreak Strikes Seattle Factory Trawler as Most of 126 Crew Tests Positive. Seattle Times.

Bloom, 2020. Bloom et 390 Professionnels du secteur de la peche, chefs et elus lancent $u$ appel citoyen au gouvernment francais pour sauvegarder la petite peche cotiere. Available from: https://www.bloomassociation.org/appel-citoyen-petite-peche/.

Campbell, S.J., Jakub, R., Valdivia, A., Setiawan, H., Setiawan, A., Cox, C., et al., 2020 Immediate impact of COVID-19 across tropical small-scale fishing communities. Ocean Coast Manag. 105485.

Center for a Livable Future, 2020. Safeguard the US Food Supply Chain during the Covid19 Pandemic, We Must Protect Food and Agricultural Workers: Recommendations for Policymakers and Employers. Johns Hopkins University.

Chenarides, L., Manfredo, M., Richards, T.J., 2020. COVID-19 and food supply chains Appl. Econ. Perspect. Pol.

China Customs. Online access platform for Customs statistics 2020. Available from: http://43.248.49.97/.

Clavelle, T., 2020. Global fishing watch, editor. Available from: https://globalfishingwa tch.org/data-blog/global-fisheries-during-covid-19/.

Coalition for Fair Fisheries Arrangements. Hard hit by the Covid-19 crisis, Ivorian women in artisanal fisheries also see it as an opportunity to address long postponed issues 2020. Available from: https://www.cffacape.org/news-blog/hard-hitby-the-covid-19-crisis-ivorian-women-in-artisanal-fisheries-also-see-it-as-an-opport unity-to-address-long-postponed-issues.

Conti, V., Cafiero, C., Sánchez, M.V., 2020. Simulating Rising Undernourishment during the COVID-19 Pandemic Economic Downturn. FAO.

Dao, T., 2020. Shrimp Problems in Vietnam Portend Possible Global Shortage. Seafood Source.

Davis, K.F., Downs, S., Gephart, J.A., 2020. Towards food supply chain resilience to environmental shocks. Nature Food 1-12.

De Silva, D., Yamao, M., 2007. Effects of the tsunami on fisheries and coastal livelihood: a case study of tsunami-ravaged southern Sri Lanka. Disasters 31 (4), 386-404.

Devereux, S., Béné, C., Hoddinott, J., 2020. Conceptualising COVID-19's impacts on household food security. Food Security 12 (4), 769-772.

Dong, E., Du, H., Gardner, L., 2020. An interactive web-based dashboard to track COVID19 in real time. Lancet Infect. Dis. 20 (5), 533-534.

European Market Observatory for Fisheries and Aquaculture Products. Coronavirus response: EUMOFA's weekly data and trends analysis. Available from. https://eu mofa.eu/covid-19.

FAO, 2018. The State of World Fisheries and Aquaculture 2018 - Meeting the Sustainable Development Goals. Rome.

FAO, 2019. FAO Yearbook: Fishery and Aquaculture Statistics 2017. Rome.

FAO, 2020. Q\&A: COVID-19 pandemic - impact on fisheries and aquaculture. Available from: http://www.fao.org/2019-ncov/q-and-a/impact-on-fisheries-and-aquacultur e/en/.

Folke, C., Carpenter, S.R., Walker, B., Scheffer, M., Chapin, T., Rockström, J., 2010. Resilience thinking: integrating resilience, adaptability and transformability. Ecol. Soc. 15 (4).

Foraker, R.E., Lai, A.M., Kannampallil, T.G., Woeltje, K.F., Trolard, A.M., Payne, P.R., 2020. Transmission dynamics: data sharing in the COVID-19 era. Learning Health Syst., e10235

Gephart, J.A., Pace, M.L., 2015. Structure and evolution of the global seafood trade network. Environ. Res. Lett. 10 (12), 125014.

Gephart, J.A., Rovenskaya, E., Dieckmann, U., Pace, M.L., Brännström, Å., 2016. Vulnerability to shocks in the global seafood trade network. Environ. Res. Lett. 11 (3), 035008.

Gephart, J.A., Cottrell, R.S., Froehlich, H., Nussbaumer, E., Stoll, J.S., White, E., 2020. Covid-19 Seafood Impacts. Zenodo.

Giannakis, E., Hadjioannou, L., Jimenez, C., Papageorgiou, M., Karonias, A., Petrou, A., 2020. Economic consequences of coronavirus disease (COVID-19) on fisheries in the eastern mediterranean (Cyprus). Sustainability 12 (22), 9406.

Global Panel, 2020. COVID-19: Safeguarding Food Systems and Promoting Healthy Diets. U.K.

Havice, E., Marschke, M., Vandergeest, P., 2020. Industrial seafood systems in the immobilizing COVID-19 moment. Agric. Hum. Val. https://doi.org/10.1007/ s10460-020-10117-6.

Hicks, C.C., Cohen, P.J., Graham, N.A., Nash, K.L., Allison, E.H., D’Lima, C., et al., 2019. Harnessing global fisheries to tackle micronutrient deficiencies. Nature 574 (7776), 95-98.
Hivrvonen, K., Abate, G.T., De Brauw, A.. IFPRI, editor2020. Available from: https ://www.ifpri.org/blog/survey-suggests-rising-risk-food-and-nutrition-insecurity-a ddis-ababa-ethiopia-covid-19.

Hobbs, J.E., 2020. Food supply chains during the COVID-19 pandemic. Can. J. Agric. Econ. https://doi.org/10.1111/cjag.12237.

Holm, P., 2012. World war II and the "great acceleration" of North Atlantic fisheries. Global Environ. 5 (10), 66-91.

Hooper, M.W., Nápoles, A.M., Pérez-Stable, E.J., 2020. COVID-19 and racial/ethnic disparities. J. Am. Med. Assoc.

Huffman, J., 2020. US Seafood Importers Scramble to Deal with Fallout from Trump's Europe Flight Limits. Undercurrent News.

Kelleher, K., Westlund, L., Hoshino, E., Mills, D., Willmann, R., de Graaf, G., et al., 2012. Hidden Harvest: the Global Contribution of Capture Fisheries. World Bank.

Kittinger, J.N., Teh, L.C., Allison, E.H., Bennett, N.J., Crowder, L.B., Finkbeiner, E.M., et al., 2017. Committing to socially responsible seafood. Science 356 (6341), 912-913.

Kleiber, D., Harris, L.M., Vincent, A.C., 2015. Gender and small-scale fisheries: a case for counting women and beyond. Fish Fish. 16 (4), 547-562.

Klotz, C., de Pee, S., Thorne-Lyman, A., Kraemer, K., Bloem, M., 2008. Nutrition in the perfect storm: why micronutrient malnutrition will be a widespread health consequence of high food prices. Sight Life Mag. 2, 6-11.

Kolding, J., van Zwieten, P.A., Marttin, F., Funge-Smith, S., Poulain, F., 2019. Freshwater Small Pelagic Fish and Fisheries in the Main African Great Lakes and Reservoirs in Relation to Food Security and Nutrition. Food and Agriculture Organization of the United Nations.

Kumaran, M., Geetha, R., Antony, J., Vasagam, K.K., Anand, P., Ravisankar, T., et al., 2020. Prospective impact of Corona virus disease (COVID-19) related lockdown on shrimp aquaculture sector in India-a sectoral assessment. Aquaculture 531, 735922.

Kummu, M., Kinnunen, P., Lehikoinen, E., Porkka, M., Queiroz, C., Röös, E., et al., 2020. Interplay of trade and food system resilience: gains on supply diversity over time at the cost of trade independency. Global Food Security 24, 100360.

Laborde, D., Martin, W., Vos, R., 2020. IFPRI, editor. Available from: https://www.ifpri. org/blog/poverty-and-food-insecurity-could-grow-dramatically-covid-19-spreads.

Laborde Debucquet, D., 2020. Food export restrictions during the Covid-19 crisis. In: (IFPRI). IFPRI.

Lebel, L., Anderies, J.M., Campbell, B., Folke, C., Hatfield-Dodds, S., Hughes, T.P., et al., 2006. Governance and the capacity to manage resilience in regional social-ecological systems. Ecol. Soc. 11 (1).

Liu, P., Yang, M., Zhao, X., Guo, Y., Wang, L., Zhang, J., et al., 2020. Cold-chain transportation in the frozen food industry may have caused a recurrence of COVID19 cases in destination: successful isolation of SARS-CoV-2 virus from the imported frozen cod package surface. Biosaf. Health.

Liverpool-Tasie LSO, Reardon T, Belton B. "Essential non-essentials": COVID-19 policy missteps in $\mathrm{N}$ igeria rooted in persistent myths about A frican food supply chains. Appl. Econ. Perspect. Pol..

Low Impact Fisheries of Europe, 2020. Covid-19 and small-scale fisheries. Available from: https://lifeplatform.eu/covid-19-and-small-scale-fisheries/.

Mamun, A., Shieh, J., Belton, B., 2020. Qualitative Assessment of COVID-19 Impacts on Aquatic Food Value Chains in Bangladesh.

Marchand, P., Carr, J.A., Dell'Angelo, J., Fader, M., Gephart, J.A., Kummu, M., et al., 2016. Reserves and trade jointly determine exposure to food supply shocks. Environ. Res. Lett. 11 (9), 095009.

Marschke, M., Vandergeest, P., Havice, E., Kadfak, A., Duker, P., Isopescu, I., et al., 2020. COVID-19, instability and migrant fish workers in Asia. Maritime Studies 1-13.

McVeigh, K., 2020. Scottish Fishermen Turn to Food Banks as Covid-19 Devastates Industry. The Guardian.

Mereghetti, M., 2020. Peru Stops Seafood Shipments to China Due to Port Logjam. Undercurrent News.

MOA, 2020. Information platform of key agricultural markets. Available from. http://zd scxx.moa.gov.cn:8080/misportal/public/agricultureStaticReportView.jsp.

Moorthy, V., Restrepo, A.M.H., Preziosi, M.-P., Swaminathan, S., 2020. Data sharing for novel coronavirus (COVID-19). Bull. World Health Organ. 98 (3), 150.

na, 2020a. Tens of Millions of Yemenis' Devastated by Unabated War and COVID-19. UN News.

na, 2020b. SPC Warns of Threat to Fisheries from Covid-19. Radio New Zealand.

na, 2020c. Canadian Gov't Declares Seafood Sector Essential during Pandemic, Follows Provinces. Undercurrent News.

Nielsen, 2020. How Americans are shopping during COVID-19. Available from: https ://www.nielsen.com/global/en/consumer-insights-for-fmcg-retail-manufacturers-co ronavirus-covid-19/how-americans-are-shopping-during-covid-19/.

Norwegian Seafood Council, 2020. Seafood from Norway. Available from. http://www. seafood.no/.

Oirere, S., 2020. South Africa Spares Fishing Industry from Lockdown Restrictions. Seafood Source.

Oliver, N., Lepri, B., Sterly, H., Lambiotte, R., Deletaille, S., De Nadai, M., et al., 2020. Mobile Phone Data for Informing Public Health Actions across the COVID-19 Pandemic Life Cycle. American Association for the Advancement of Science.

Open Table, 2020. The state of the restaurant industry. Available from. https://www.op entable.com/state-of-industry.

Österblom, H., Jouffray, J.-B., Folke, C., Crona, B., Troell, M., Merrie, A., et al., 2015. Transnational corporations as 'keystone actors' in marine ecosystems. PLoS One 10 (5).

Pothan, P.E., Taguchi, M., Santini, G., 2020. FAO editor.

Ramirez, E., 2020. Generosity in Time of COVID-19: Fishermen in Mexico Donate Tons of Fresh Fish to the Community. SAMDURA News Alerts. 
Ramsdan, N., 2020. Coronavirus May Help Spur Aquaculture Investments in Africa. Undercurrent News.

Reardon, T., Mishra, A., Nuthalapati, C.S., Bellemare, M.F., Zilberman, D., 2020. Covid19 's disruption of India's transformed food supply chains. Econ. Polit. Wkly. 55 (18), $18-22$.

Reuters, 2020. Ghana President Says One Person Infected 533 with Coronavirus at Fish Factory. Reuters.

Rizou, M., Galanakis, I.M., Aldawoud, T.M., Galanakis, C.M., 2020. Safety of foods, food supply chain and environment within the COVID-19 pandemic. Trends Food Sci. Technol. 102, 293-299.

Rosen, L., 2020. Impacts of COVID-19 on Aquatic Food Supply Chains in Bangladesh, Egypt, India, Myanmar, Nigeria and Timor-Leste, February-April 2020.

Rubio, A., Schreiber, J., 2020. Ecuador Farmed Shrimp Exports in. Urner Barry.

Seaman, T., 2020. Undercurrent News. Russian Pollock Firms Adapt to Quarantine Measures as Fishing Continues in Country's Paid Week off.

Seaman, T., Harkell, L., 2020. Chile, Norway Sellers Redirect Salmon to US as Coronavirus-Hit China Cancels Orders. Undercurrent News.

Seekell, D., Carr, J., Dell'Angelo, J., D’Odorico, P., Fader, M., Gephart, J., et al., 2017. Resilience in the global food system. Environ. Res. Lett. 12 (2), 025010.

Seshagiri B, Nagireddy M, Raju VR, Nagireddy S, Rangacharyulu P, Rathod R, et al. Impact of Nationwide Lockdown on Freshwater Aquaculture in Andhra Pradesh, India.

Smith, S.L., Golden, A.S., Ramenzoni, V., Zemeckis, D.R., Jensen, O.P., 2020. Adaptation and resilience of commercial Fishers in the Northeast United States during the early stages of the COVID-19 pandemic. Plos One 15 (12), e0243886.

Sorensen, J., Echard, J., Weil, R., 2020. From bad to worse: the impact of COVID-19 on commercial fisheries workers. J. Agromed. 1-4.

Standard Team, 2020. For Nyanza Fishermen, it Is the Best and Worst of Times. Standard.

Steenbergen, D.J., Neihapi, P., Koran, D., Sami, A., Malverus, V., Ephraim, R., et al., 2020. COVID-19 restrictions amidst cyclones and volcanoes: a rapid assessment of early impacts on livelihoods and food security in coastal communities in Vanuatu. Mar. Pol. 121, 104199.

Stoll, J.S., Harrison, H.L., De Sousa, E., Callaway, D., Collier, M., Harrell, K., et al., 2020. Alternative Seafood Networks during COVID-19: Implications for Resilience and Sustainability.

Sumner, A., Hoy, C., Ortiz-Juarez, E., 2020. Estimates of the Impact of COVID-19 on Global Poverty. United Nations University.
Tendall, D., Joerin, J., Kopainsky, B., Edwards, P., Shreck, A., Le, Q.B., et al., 2015. Food system resilience: defining the concept. Global Food Security 6, 17-23.

The International Collective in Support of Fishworkers, 2020. Addressing the impact of the COVID-19 pandemic on fisheries and fishing communities. Available from: http s://covid.icsf.net/.

Torlesse, H., Kiess, L., Bloem, M.W., 2003. Association of household rice expenditure with child nutritional status indicates a role for macroeconomic food policy in combating malnutrition. J. Nutr. 133 (5), 1320-1325.

Troell, M., Naylor, R.L., Metian, M., Beveridge, M., Tyedmers, P.H., Folke, C., et al. 2014. Does aquaculture add resilience to the global food system? Proc. Natl. Acad. Sci. Unit. States Am. 111 (37), 13257-13263.

UN FAO, 2020. COVID-19 dampens the initially positive shrimp forecast for 2020. Available from: http://www.fao.org/in-action/globefish/market-reports/resource -detail/en/c/1296667/.

United Nations, 2017. UN comtrade database. Available from. https://comtrade.un.org/.

United Nations, 2020a. Policy Brief: the Impact of COVID-19 on Food Security and Nutrition. Rome.

United Nations, 2020b. Policy Brief: the Impact of COVID-19 on Food Security and Nutrition: Developing Effective Policy Responses to Address the Hunger and Malnutrition Pandemic. Rome.

USDA, 2020. Food expenditure series. Available from. https://www.ers.usda.gov /data-products/food-expenditure-series/.

van Senten J. Effects of COVID-19 on US aquaculture farms. Appl. Econ. Perspect. Pol..

Vella, F., Senia, P., Ceccarelli, M., Vitale, E., Maltezou, H., Taibi, R., et al., 2020. Transmission mode associated with coronavirus disease 2019: a review. Health 1, 2.

White, C., 2020. Alaska's Seafood Processors Hit Hard by COVID-19 Costs. Seafood Source.

White, E.R., Froehlich, H.E., Gephart, J.A., Cottrell, R.S., Branch, T.A., Agrawal Bejarano, R., et al., 2020. Early Effects of COVID-19 on US Fisheries and Seafood Consumption. Fish and Fisheries.

World Food Programme, 2020. Targeting and Prioritization of Impoverished and FoodInsecure Populations Affected by COVID-19.

WorldFish, 2020. COVID-19 impacts on fish and aquatic food systems. Available from: https://www.worldfishcenter.org/pages/covid-19/.

Xia, R., 2020. Environmental Groups Urge Americans to Eat More Fish while Hunkering Down against Virus. Los Angeles Times. 